\title{
Improving the 5th Formers' Continuous Writing Skills through the Creative Writing Module
}

\author{
Mohana Ram Murugiah \\ Smk Perempuan Methodist, Ipoh, \\ No, 2 Jalan Raja Permaisuri Bainun \\ 30250, Ipoh Perak \\ E-mail: mohanaram_2000@yahoo.com
}

Doi:10.7575/aiac.alls.v.4n.2p.7

URL: http://dx.doi.org/10.7575/aiac.alls.v.4n.2p.7
Received: 02/04/2013

Accepted: 04/06/2013

\begin{abstract}
Writing is a complex task. The development of students' writing skill depends on the teacher's teaching strategy and also the materials used in the writing lesson. In the present study, the effectiveness of a creative writing module was examined that was designed to improve the writing skill of a group of excellent students. It was added with explicit teaching strategies. The selected group of students were students who were in the excellent group but lacked creativity and vocabulary in their writing. The creative writing module was designed to help these students. Students' improvement was observed through observation in the classrooms during the lessons and through writing task as well as interviews. Two observations were made. One was before the creative writing project was started and another after the completion of the entire task of the module. The interview was carried out to learn about the students' perception of the module and how do they find the module has helped them. The result of the research showed that students have shown a great level of improvement in their writing skills. The outcome of this present study could be useful to assist language instructors in helping proficient learners to undergo a more effective second language learning experience.
\end{abstract}

Keywords: writing skills, creative writing, observation, module, writing tasks

\section{Introduction}

The purpose of this study was to explore the effectiveness of teaching the Creative Writing through the use of the Creative Writing Module which was developed to aid a group of excellent students to improve their creativity and vocabulary in writing.

Writing does not only involve transformation of language into written signs. But it is a thinking process which involves conscious effort and time at the part of the writer. Writing becomes necessary when one wants to express his ideas into written form of the language (Syed, 2007). (White, 1980) has defined writing as a means of communication with stylistic appropriateness and formal correction in which the ability to write logically and grammatically connected sequences of sentences is fundamental.

Creative writing has become increasingly popular since the 1960s in schools and seen as the judgment of literacy. It allows students to use their imaginative and creative ways to describe their thoughts and ideas. Creative writing also requires the mastery of other sub- skills which is essential to convey the ideas coherently such as spelling, the organization of ideas, paragraph construction, and the use of linking devices to show cohesion and the ability to manipulate words, structures and sentences (Osborn, 2005).

There are views that stated that creative writing is a natural ability and cannot be taught. However, I believe that the ability to write creatively can be molded through consistent and effective lessons which led me to develop my creative writing module entitled 'Creative Writing with Mohana'. This module was developed with a reminder that a teacher should focus on the effective use of language in teaching writing. The module was developed to aid a group of excellent high school students who can write well but lack vocabulary and creativity. Therefore, the module focused on the effective use of words, phrases and sentences in a variety of tasks. Different strategies for teaching writing like modeling the writing process, imitating written text, or joint construction of texts and practice in independent writing, will help the students get confidence over their writing and become prolific writers (Winch et al, 2006).

In what follows, it is briefly discussed how the creative writing module aided with explicit teaching strategies improved students' writing skills to a greater height.

\section{Literature Review}

Similar researches on the teaching of creative writing with the aid of a module were very limited; perhaps this form of research is not favored by many researchers. However, there are few researches that were slightly connected to my research were found and elaborated in this section. 
Craik and Lockhart (1972) have postulated that the research on Creative writing aids language development at all levels: grammar, vocabulary, phonology and discourse. As learners manipulate the language in interesting and demanding ways, attempting to express uniquely personal meanings (as they do with creative writing), they necessarily engage with the language at a deeper level of processing than with expository texts (Craik and Lockhart 1972). This idea has been explored and well adapted in the creative writing module building process where every aforementionedthat aspects were given equal importance.

A research on the uses of reflective and creative writing in health care education classrooms and professional development setting was carried out (Kerl 2010) and review of article related to writing for health care revealed that when teaching narrative competence is the goal, creative writing may produce the best outcomes. Ultimately, the paper describes the importance of defining literary creative writing as a distinct form of writing and recommends scholars interested in using literary creative writing to teach narrative competence study pedagogy field. This paper is evidence that creative writing has the power to produce better outcomes and gives the purpose for me to create a creative writing module to improve my students' continuous writing skills.

Some scholars believed that in creative writing task, like a poetry book, enables ESL students to develop their voices and identity as a second language writer in their writing (Chamcharatsri, 2009; Hanauer, 2004, 2010, 2011; Iida, 2008, 2010). In other words, creative writing is one of the possible approaches that can be used in ESL/EFL contexts. By exploring the relationship between the writing experiences that the students have experienced through the creative writing module and their perceived ability in creative writing, this research aims to contribute some knowledge to the field of teaching writing to ESL/EFL students.

Chamcharatsri (2009) pointed out that creative writing shares close relation to expressive pedagogy. Expressive pedagogy can allows students to gain a greater awareness of process in writing while providing opportunities to develop the ability to take responsibility and take control over their own writing. Moreover, Fernsten (2008) described that the expressivism suggests that the ability to write comes not from the memorization but from the true expression of our innermost thoughts. In other words, expressive pedagogy is used in teaching creative writing, and it enables the ESL students to gain the ownership in writing their inner thoughts. Therefore, we can say that there is a strong relationship between the writers' voices and their writing. Although, the points mentioned here bring deeper meaning and related to the higher level of creative writing, the module that was built to teach creative writing has the fundamental elements which have taught the students how to write creatively. After all, the prerequisite here is to learn how to write creatively before allowing one's own creative juices to flow freely.

Schultz's (2001) has discussed the general benefits of creative writing. He presented that, 'Creative writing urges students to form and shape the raw material of experience into an artistic and compellingly executed format. By doing so, students can improve both their speaking and reading skills ( Schultz,2001).Second, creative writing is a process of liberation and it provides students with "a distance from themselves that allows them to dare and to try new things, something they often will not do in the concretized identity associated with their native language"(Schultz,2001). Third, Schultz (2001) has also stated that in creative writing the intensity of the commitment to the specifics of the foreign language goes well beyond that elicited by writing assignments where students are instructed to use vocabulary from a textbook list or grammar from a given lesson. This has given the relevance to my purpose to build a creative writing module to help and guide my students to improve their continuous writing skills.

Research shows what students can benefit from creative writing projects, but still, some different arguments exist. Light (2002), mentioned the reason for creative writing regarded as not proper to be taught in learning institution is that "creative writing is not 'serious' and encourages self-indulgence". Also, Chamcharatsri (2009) pointed out that some scholars may argue creative writing for its "nonserious and nonacademic-ness". As I present above for the concepts about creative writing, these claims prove to be irrational and fallacious.

There are some researchers held a different point of view towards the use of creative writing, but it provides the different perceptions towards the value of creative writing, and it is worthy of being investigated.

Creative writing as I have presented in this section, shows that creative writing can improve students' language competence (Hanauer, 2003; Iida, 2011) including writing competency. This study was conducted in order to explore the effectiveness of using a creative writing module to improve ESL students' narrative writing skills.

\section{Methodology}

The goal of this study is to encourage both teachers and educational institutions to notice and regard creative writing as one of the approaches to improve students writing skills with regards of vocabulary and creativity in writing. The purpose of this study is to explore the effectiveness of the use of creative writing module in the writing classroom. One issue is whether applying creative writing in ESL context is beneficial to ESL students or not; and if so what do the students think about the creative writing module. In order to achieve this goal, the study was conducted using a qualitative interview and observation design with a group of fifth formers (year 11). The research questions in this study are as follow:

a) Does the creative writing module help students to write creatively? And.....

b) Does the module help to improve students' narrative writing skills?

This section details the information of participants and the research design.

\subsection{The Creative Writing Module}

The Creative writing module was designed to cater the students' need in improving their writing skills. The module was designed in a step - by - step exercises where students learn from the basic exercises till the advance writing level. The first few exercises focused on building sentences using impressive words and phrases creatively. These exercises were 
not independent exercises but teacher guided practices and group practices where students worked in groups to complete the task some exercises require the teacher to be there to guide the students to complete the task so that they will be able to use the phrases and words given precisely.

The second level of the writing module was exercises requiring the students to move to another level of creative sentence construction. In this level students were exposed to a variety of sentences with high level of creativity describing people, nature or events. Students were given a variety of samples before they were guided to their own task of writing.

The next level of the module required students to complete a number of simple writing tasks where the students needed to use words, phrases and sentences to complete the tasks. Students will be given the task in a form of a situation described in simple sentences and the students were required to transform it using interesting phrases and words. These tasks were repeated a few times till students were really comfortable with the task given.

Students were given many exercises in the same forms to make them feel comfortable with the phrases that they use. The final practice of the exercises was writing short stories. Students were required to write short stories using the phrases and sentences that they have learnt all the while. For this level students were required to write independently and the teacher only facilitates the students.

\subsection{Research Design}

This study was conducted as an interview and observation based qualitative design. Barbour (1999) stated that qualitative methods can illuminate the variety of meanings attached by different individuals related to particular events or issues. This can be from the training or experiences they had and these can help them to provide different understandings and perspectives. Black (1994) stated that a holistic perspective can be obtained through qualitative methods which will be able to preserve the complexities of human behavior. Moreover, Cohen, Manion, and Morrison (2011), stated that both interviewers and interviewees can freely give their own point of views of the topics which is being discussed through interviews. In order to answer the research questions, the study aims to discover the research questions at the students' perspectives. Since, each student has their own ability and perceptions, therefore a qualitative interview and students' task observation was conducted in this study. In this research, the data that were collected are qualitative based and the interview questions was dealt with students' ability to write after using the creative writing module.

\subsection{Participants}

The research participants comprised of 36 non - native English speaking students from a secondary school in Sarawak. The students were in form 5 (Year 11).All the participants were from the same class and excellent students who were expected to get straight A's in the public examination known as Sijil Pelajaran Malaysia (SPM) that they were to take on that year, which will determine their future undertakings. English is either their second or third language. Their English level was between pre - intermediate to advanced level. The rationale for selecting this group of students was because the module was built to improve their writing skills after it was noticed that they lack vocabulary and impressive words in their compositions especially narratives. Since the module was built for them, the students were taken as the research participants. The students underwent several creative writing lessons from June 2012 till September 2012 during and after their class hours. Each lesson lasted for about 120 minutes every week and attendance was not a problem although some of the lessons we conducted outside the school hours. They did a number of tasks in groups and also individually. Students' performance was evaluated through observation of the task given to them and the SPM trial examination. Besides, the interview was carried out by some of the students who were picked randomly.

\subsection{The interview}

In order to know my participants perspective on the creative writing module, the interview questions were designed to elicit the participant's view as well as their opinion of the module and how the module has helped them to write better than before. The research questions are not elaborated here. 15 students were picked randomly for one - to - one interview session. The aim of the interview was getting first-hand unbiased information from students on their perception of the creative writing module and how it has helped them. Also questions were asked about how they have benefitted from the module. The interviews were recorded and transcribed. The questions were designed as open ended questions so that it could warm up the conversation in a casual way, in which participants were free to share their experiences of using the creative writing module to help them to improve their writing skills. To get the answer for my research the following questions were: asked:

Table $1:$ The interview questions

a As a student, how do you think the module has benefitted you?

b Do you think your writing skill has improved after using the module? If yes in what ways?

c What kind of difficulties did you face when you started using the module and how did you overcome them?

d Are you confident with what you have learnt from the creative writing module

e What is the difference do you see in your compositions before and after you have started using the module?

$\mathrm{f}$ Is there any part of the module that you think should be amended for improvisation?

$\mathrm{h}$ Did you practice the contents of the modules on your own after the lessons? 


\subsection{The observation}

Fox (1998) has stated that Observational method is more than just recording of data from the environment. When we observe, we are active, not passive collectors of data like a tape recorder or video camera. Our brains are engaged as well as our eyes and ears, organising data so we can make sense of them (Fox, 1998). Moreover, Patton (1990), Fox (1998), Kawulich (2005) and Mack et al. (2005) when using observation as a means to gather data as they have averred in their papers that opting this type of method allows researchers to explore and get information which are more truthful and natural.

The purpose of the observation was to check and confirm students' improvement from time to time after the use of the module commenced. It took four months for us to complete all the exercises in the module and students' progress was observed from time to time after a few exercises and discussions. The observation was made through exercises given to the students and through independent writing tasks which was given in between a few lessons. The results of the observation were recorded through a chart and the final observation was made on the student essay that they wrote during their SPM English trial paper in October it was compared with the mid year examination. The mid year examination was taken to be compared with the latest results because the students were only exposed to the module and they started using it intensively after the mid- year examination. The data were collected through pre and post observation. The pre and post observational list was used to measure the results. The interest and understanding level of the students was examined through observation. During observations a checklist was used. The checklist includes skills that researchers hope to see in students.

\section{Procedure}

\subsection{The Teaching Strategy}

The Creative writing module would not be a success if it was not complemented with explicit teaching strategies. The teaching strategies for Rosenshine (1986) have stated that students need a good deal of practice when learning new material, and effective teachers find ways to provide it with proper teaching strategies. Rosenshine (1986) has summarized 6 effective teaching functions which have been practiced when the creative writing module was used to teach in the classroom. The functions are; reviewing, presentation of new material, guided practice, feedback and corrections, independent practice and weekly and reviews of the lesson. Similar functions have also been developed by Good and Grouws (1979) and Russell and Hunter (1981). These 6 functions were the basis of the explicit teaching strategy that was used in the lessons that made the lessons to be successful. These teaching functions represent some of what Gage (1978) calls 'the scientific basis for the art of teaching'. The six functions that were used during the lessons have been summarized in the teaching process table below.

Table 1. Lesson procedures based on Rosenshine, B. (1986). Synthesis of research on explicit teaching

\begin{tabular}{|l|l|}
\hline \multicolumn{2}{|c|}{ Teaching of Creative writing : The Teaching Process } \\
\hline Review & $\begin{array}{l}\text { Review of the homework or relevant previous learning. Review prerequisite } \\
\text { skills and knowledge for this lesson. The teacher spent about five to eight } \\
\text { minutes to review of previous materials, correction of homework and review } \\
\text { of relevant prior knowledge. }\end{array}$ \\
\hline Presentation & $\begin{array}{l}\text { State lesson goal and/or provide an outline. Teach in a step - by - step } \\
\text { manner and provide concrete positive examples and negative examples. They } \\
\text { use clear language check for student understanding. Avoid digressions }\end{array}$ \\
\hline Guided Practice & $\begin{array}{l}\text { High frequency of questions or guided practice Ail student respond and } \\
\text { receive feedback. Continue practice until students are able to understand and } \\
\text { able to apply correctly. }\end{array}$ \\
\hline Corrections and Feedback & $\begin{array}{l}\text { Give process feedback when answers are correct and reteaching for incorrect } \\
\text { answers. Provide teaching whenever necessary. }\end{array}$ \\
\hline Independent practice & $\begin{array}{l}\text { Students receive help during initial steps, or the overview. The teacher } \\
\text { provides active supervision and observation of tasks. Routines are used to } \\
\text { help slow learners. }\end{array}$ \\
\hline Weekly and monthly review & $\begin{array}{l}\text { Reviews are done in the form of weekly and monthly assessment to test } \\
\text { students' understanding and are recorded in the observation chart. }\end{array}$ \\
\hline
\end{tabular}

The aforementioned steps were applied to modification to suit learners and the tasks throughout the lessons that was carried out using the creative writing module. The teaching approach was not teacher - centred but was student centered. Activities such as filling in the gap, matching phrases, matching simple phrases with creative phrases, group writing activity, writing with a partner activity, and rewriting phrases were among the activities that were carried out.

\section{Findings and discussions}

Based on the data that was collected it was found that students have shown positive response on the use of creative writing module in order to improve their writing skills. 


\subsection{Finding through the observation}

Through the pre and post observation it was found that a large number of the students have shown improvement in term of using creative expressions in their compositions which most of the ideas were learned from the writing modules (refer to Appendix A for the pre and post observation record). Through the pre and post observation record it can be seen that $97 \%$ of the students have shown improvement in their continuous writing task. In the previous test the students only scored $27-34$ marks but in the SPM trial examinations most of the students have scored 40 to 45 marks and a few score 47 and 48 marks. This was a tremendous achievement. From the classroom observation it was found that student had difficulty in adapting themselves to the module when it was first introduced to them as they were not used to the words and expressions which was something very new but as the lesson moves on from one place to another, the students have started to accept it and some even went to the extend to memorize the phrases and expressions that they have learnt in the modules. Observation in the written task showed that students had problems in the beginning with the use of the newly introduced creative phrases and some did not even use them until they were forced to use. They made errors such as misspelled words, wrong usage of expressions and grammatically wrong phrases which were the result of copying directly from the module without any modifications.

It was difficult in the beginning and I thought I have failed but I did not give up. I constantly reminded them of the mistakes that they have made and helped them to correct their mistakes so that I would not be repeated. However, it took time for the students to learn. They made the same mistakes time and again but after a few lessons and after they have used them in their written practices numerous times, the errors started to decrease.

\subsection{Findings through the interview}

From the interview it was found that students had difficulties in accepting the contents of the modules in the beginning as they felt it was not to their level. They had no confidence in using the module at first, but with proper guidance and explanation from the teacher they have learnt to understand the use of the ideas in the module. Students also stated that they found it was very difficult in the beginning as there were too many difficult words that they have never come across before and had to always refer to a dictionary which they stated to be quite troublesome, but after some time they got used to it and enjoyed learning the new expressions. They also stated that they had a great amount of difficulty in understanding the phrases because as a word they stood alone but when they were put together as phrases they brought in different meanings. The students also stated that after they got used for the module they were quite excited to experiment the newly learnt words and phrases in their composition but not all some of them stated they were not confident enough to use them without guidance from a teacher but they did attempt when they were forced to. Through the interview as well it was found that students felt that they have improved in their composition writing tremendously when they could use the phrases and the ideas correctly in their composition and had a sense of achievement which motivated them to experiment more in their written exercises. Some even stated that they have started using them in their daily conversations. The students stated that they were much confident in their writing ability than they were before after they had completely done with the practices in their module and all set for their SPM English.

\section{Conclusion}

The purpose of this study was to explore the effectiveness of the creative writing module which was designed to help a group of excellent students who were lacking ideas and vocabulary in their compositions. Whether the module served the purpose or not was the question that was raised in this research. Data was collected and validated through observations and interviews. The finding of the study indicated that the use of the creative writing module has helped the students to use a wide range of vocabulary and interesting phrases in the continuous writing. Students demonstrated good use of the ideas that were taught through the creative writing module which were complemented with explicit teaching strategies. Students had problems in the beginning to adapt themselves to the wide range of difficult words and phrases used in the module. However, as the lesson moves from one place to another the students manage to adapt themselves and felt comfortable when the lessons were carried out with explicit teaching strategies. The module alone would have not been able to help the students to improve if it was not complemented with a systematic teaching strategy.The students who were involved in this project showed tremendous improvement when their SPM trial results were compared with the mid - year examination. Almost $97 \%$ of the students scored excellent marks for the continuous writing component scoring more than 42 marks over 50. In the SPM 2012 examination 29 out of 36 students involved in the research scored $\mathrm{A}+$ and 7 students scored As. I believe that the extensive use of the creative writing Module for over 6 months has contributed in helping the students to score and $100 \%$ As in the major public examination.

In a nutshell, the use of the creative writing module with the explicit teaching strategy that was implemented in the class has helped the students to improve their writing skill.

\section{References}

Barbour, R. S. (1999). The role of qualitative research in broadening the 'evidence base' for clinical practice. Journal of Evaluation in Clinical Practice, 6(2), 155-163.

Black, N. (1994). Why we need qualitative research. Journal of Epidemiology and Community Health, 48, 425-426.

Cohen, L., Manion, L., \& Morrison, K. (2011). Research methods in education ( $7^{\text {th }}$ edition). New York, NY: Routledge.

Chamcharatsri, P. (2009). Second language writers and creative writing. TESOL, 4(2). Retrieved Nov 17, 2010, from http://www.tesol.org/s_tesol/sec_issue.asp?nid=4116\&iid=12800\&sid=1 
Craik, F.I.M and R.S. Lockhart (1972) 'Levels of processing : a Framework for memory research.' Journal for verbal learning and Verbal Behaviour II : $617-84$.

Fox, N. J. (1998). How to use observations in a research project. NHS Executive, Trent.

Liao, F. Y. (2012). Esl Students'writing Experiences And Perceived Poetry Writing Ability (Doctoral dissertation, Indiana University of Pennsylvania).

Fernsten, L. (2008). Writer identity and ESL learners. Journal of Adolescent \& Adult Literacy, 52(1), 44-52.

Gage, N L The Scientific Basis of the Art of Teaching New York Teachers College Press, 1978.

Good, T L, and D A. Grouws "The Missouri Mathematics Effectiveness Project” Journal of Educational Psychology 71 (1979) 143-155.

Hanauer, D. (2011). The scientific study of poetic writing. Scientific Study of Literature, 1(1), 79-87.

Hanauer, D. (2010). Poetry as research. Philadelphia: John Benjamins.

Hanauer, D. (2004). Poetry and the meaning of life. Toronto: Pippin.

Iida, A. (2010). Developing voice by composing haiku: A social-expressivist framework for teaching haiku writing in EFL contexts. English Teaching Forum, 48(1), 28-34.

Iida, A. (2008). Poetry writing as expressive pedagogy in an EFL context: Identifying possible assessment tools for haiku poetry in EFL freshman college writing. Assessing Writing, 13, 171-179.

Kawulich, B. (2005). Participant Observation as a Data Collection Method [81 paragraphs]. Forum Qualitative Sozialforschung/Forum: Qualitative Social Research, 6(2), Art. 43, Retrieved at http://nbnresolving.de/urn:nbn:de:0114-fqs0502430.

Kerr, L. (2010). More than words: applying the discipline of literary creative writing to the practice of reflective writing in health care education. Journal of Medical Humanities, 31(4), 295-301.

LeNoir, D. (2002). The multigenre warning label. The English Journal, 92(2), 99- 101.

Light, G. (2003). From the personal to the public: Conceptions of creative writing in higher education. Higher Education, 43(2), 257-276.

Mack, N., Woodsong, C., MacQueen, K. M., Guest, G., \& Namey, Emily (2005). Qualitative research method: A data collector's guide. Family Health International.U.S. Agency for International Development (U.S.AID).

Patton, M. Q. (1990). Qualitative evaluation and research methods (2nd ed.), Newbury Park, CA: Sage Publications Inc.

Rosenshine, B. (1986). Synthesis of research on explicit teaching. Educational Leadership, 43(7), 60-69.

Russell, D, and Hunter, M. (1981). Planning for Effective Instruction Lesson Design” In Increasing Your Teaching Effective-ness Palo Alto The Learning Institute,

Schultz, J. M. (2001). Toward a pedagogy of creative writing in a foreign language. In G.Brauer (Ed.), Pedagogy of Language Learning in Higher Education: an introduction(pp. 93-108). Westport, CT: Ablex Publishing.

Tin, T. B. (2011). Language creativity and co-emergence of form and meaning in creative writing tasks. Applied Linguistics, 32(2), 215-235. 